\title{
The Carbon Budget Model of the Canadian Forest Sector (CBM-CFS3): customization of the Archive Index Database for European Union countries
}

\author{
Roberto Pilli ${ }^{1}$ (D) Stephen J. Kull ${ }^{2} \cdot$ Viorel N. B. Blujdea ${ }^{3} \cdot$ Giacomo Grassi $^{1}$
}

Received: 14 August 2017 / Accepted: 18 May 2018 / Published online: 2 July 2018

(C) The Author(s) 2018

\begin{abstract}
- Key message The purpose of this report is to increase the transparency of applications of the CBM-CFS3 model by climate-related policy-makers and researchers. The report provides explicit information on the parametrization of a new Archive Index Database used with this model to simulate forest carbon dynamics in $26 \mathrm{EU}$ countries. The database can be accessed at https://data.europa.eu/89h/jrc-cbm-eu-aidb, primary metadata are available in Kull et al. (2017), and additional metadata are available at https://metadata-afs.nancy.inra.fr/geonetwork/srv/fre/catalog.search\#/metadata/ df48155b-973f-4169-a722-100bb6bfc76c.

The Carbon Budget Model of the Canadian Forest Sector (CBM-CFS3) has been adapted, tested, and applied to forests of $26 \mathrm{EU}$ countries over the last 7 years for EU policy making and scientific research. The overall purpose of this exercise is to increase the transparency of how the EU Archive Index Database (EU-AIDB) was parameterized while supporting both the policy making and research communities interested in applying the CBM-CFS3 with ecological parameters specific to the EU context. In addition to preparing model input data reflecting various management and disturbance scenarios for CBM-CFS3 projects, an essential step was to update the original AIDB with information specific to the EU context and create an EU-AIDB. The AIDB is the Microsoft Access database behind the CBM-CFS3 that stores default ecological information and parameters pertaining to the forest ecosystems of a country, among other functions. The EU-AIDB incorporates 1034 spatial units resulting from the intersection of 204 European administrative regions and ecological boundaries representing 35 climatic units. It also contains updated parameters for 192 of the main tree species reported by the National Forest Inventories of each EU country. The release of this database allows CBM-33 CFS3 users in the EU to apply European administrative and ecological units and tree species in forest carbon modeling projects.
\end{abstract}

Keywords CBM-CFS3 · Archive Index Database $\cdot$ European Union $\cdot$ Forest $\cdot$ Carbon accounting

Handling Editor: Aaron R. Weiskittel

Contribution of the co-authors RP prepared the database in collaboration with VB and SK. RP, SK, and VB wrote the manuscript in collaboration with GG. All authors read and approved the final manuscript.

Electronic supplementary material The online version of this article (https://doi.org/10.1007/s13595-018-0743-5) contains supplementary material, which is available to authorized users.

Roberto Pilli

roberto.pilli@ec.europa.eu

1 Directorate D, Bioeconomy Unit (D1), European Commission - Joint Research Centre (JRC), Ispra, Italy
2 Natural Resources Canada, Canadian Forest Service, Northern Forestry Centre, 5320122 Street, Edmonton, AB T6H 3S5, Canada

3 Faculty of Silviculture and Forest Engineering, Transilvania University of Brasov, Sirul Beethoven 1, 500123 Brasov, Romania 


\section{Introduction}

Modeling a forest carbon budget is generally considered an essential prerequisite to providing projections on different possible management scenarios in order to optimize the role of the overall forest sector in mitigating climate change (IPCC 2014). For the purposes of analyzing the impact of human activities on the current and near-future forest carbon (C) stocks and fluxes, inventory-based models are the most appropriate tools (Karjalainen et al. 2003).

For this reason, the Joint Research Centre (JRC) of the European Commission has been applying and testing the Carbon Budget Model of the Canadian Forest Sector (CBMCFS3), developed by Natural Resources Canada's Canadian Forest Service (CFS), since 2009. This model (http://www. nrcan.gc.ca/forests/climate-change/carbon-accounting/13107), its user's guide, and supporting technical documentation are all available free-of-charge online, and technical support and training is available from the CFS.

The CBM-CFS3 is an inventory-based, yield data-driven model that simulates the stand- and landscape-level $\mathrm{C}$ dynamics of above- and belowground biomass, dead wood, litter, and mineral soil (Kurz et al. 2009). The model has already been applied and validated at regional and national scales in Canada (Kurz and Apps 1999; Kurz et al. 2008a, b; Stinson et al. 2011), and in other countries (e.g., the Russian Federation (Zamolodchikov et al. 2008), and South-Korea (Kim et al. 2016)).

The model has been adapted and used to simulate forest $\mathrm{C}$ dynamics in 26 European Union (EU) member states (Pilli et al. 2016), excluding Cyprus (no national forest inventory (NFI) data available), and Malta (negligible forest area). This modeling represented particular characteristics of European forests, including (i) uneven-aged forest management (Pilli et al. 2013); (ii) a large variety of other management systems (e.g., coppice, coppice with standards, and shelterwood); and (iii) the use of national standing volume and annual increment data.

The basic structure of the CBM-CFS3 includes three tools (Kull et al. 2016): (i) the MAKELIST preprocessing program, used to format the inventory information and initialize the dead organic matter (DOM) pools; (ii) the CBM processing program, used during the simulation period to calculate the $\mathrm{C}$ stocks of each pool and spatial unit (SPU) annually, over the simulation period, according to the input data provided by the user; and (iii) the Archive Index Database (AIDB), a Microsoft Access database that tracks the relationship between the model inputs and the results, tracks the status of the simulations, and stores all of the default information and parameters applied by model when creating a new project. Both MAKELIST and the CBM are executable files which process the information provided by the user. The CBM-CFS3 has a user-friendly interface, permitting the user to modify the default (Canadian) data and parameters assigned to a specific project; however, to efficiently apply local data and parameters (i.e., non-default) to all projects made with the model, particularly when it will be applied frequently to forest ecosystems outside of Canada, modifying the content of the AIDB is the best path to follow. As such, the contents of the AIDB were partially modified to better correspond to the European context. This preliminary work provided elements for the parametrization of the model, which leads to the validation of the CBM-CFS3 at the regional and national levels in various countries (Pilli et al. 2014, 2016).

The aim of this report is to share the information included in the EU-AIDB created and applied by the JRC to CBMCFS3 projects for EU countries. The EU-AIDB can be downloaded through the following website: http://data. europa.eu/ $89 \mathrm{~h} / \mathrm{jrc}-\mathrm{cbm}-\mathrm{eu}-\mathrm{aidb}$. The intent of sharing this information is to increase the transparency of our research and allow others to apply the CBM-CFS3 with the EUAIDB at national and local scales, to serve their needs.

\section{General model description}

The CBM-CFS3 is a dynamic simulation model that can represent a wide range of forest management activities, land-use changes, and natural disturbances. The model provides annual time step projections of $\mathrm{C}$ stocks in living biomass, dead organic matter, and mineral soil $\mathrm{C}$ pools, fluxes among the $\mathrm{C}$ pools to the forest products sector, and to atmosphere, and ecological indicators, such as net primary productivity and net ecosystem productivity.

The model framework conceptually follows IPCC Reporting Method 1 (Penman et al. 2003) in which spatial units (SPUs) are defined by their geographic boundaries in a non-spatially explicit manner. Each forest stand is characterized by an age, area, and up to 10 classifiers, is linked to an appropriate yield curve(s), and is associated with a specific SPU. Each SPU is linked to specific biomass proportions and turnover rates, DOM, climate, and natural and managed disturbance parameters in the model. Ideally, the user should also have other information on-hand related to forest succession, disturbance types occurring on their landscape, and alternate management strategies (Kurz et al. 2009). Such data are typically provided by NFIs.

To create a project in the CBM-CFS3, the user must import a library of yield curves which define for each species or forest type, age-dependent, gross merchantable volume standing stocks. These curves represent the volume dynamic in the absence of natural disturbances and management practices. When the curves are imported into a CBM-CFS3 project, speciesspecific, stand-level volume-to-biomass equations (Boudewyn et al. 2007; Canada's National Forest Inventory 2016) convert the merchantable volumes into several different aboveground biomass $\mathrm{C}$ components (merchantable stems, bark, branches, foliage, and non-merchantable biomass). The increment and annual turnover of belowground biomass are calculated using equations provided by Li et al. (2003). Annual deadwood and 
foliage inputs into DOM pools are estimated as a percentage (i.e., turnover rate) applied to the standing biomass $\mathrm{C}$ stocks.

During each CBM-CFS3 project simulation, the model applies a set of natural and/or anthropogenic disturbances (as directed by the user in their project inputs), such as forest fires, insect disturbances, partial cutting, and clear-cut harvesting. To implement these disturbances, the user defines, for each time step: (i) eligibility criteria for target stands such as forest type, and age range (Kull et al. 2016), and (ii) the efficiency of the disturbance, the target type (area, percentage of eligible records, or tonnes of merchantable $\mathrm{C}$ ), the amount to disturb, and the disturbance type. The impact of each disturbance on each $\mathrm{C}$ pool is defined by the user with what is termed a "disturbance matrix" (Kurz et al. 1992). A disturbance matrix defines the proportion of $\mathrm{C}$ transferred between $\mathrm{C}$ pools as a result of the disturbance, within the forest ecosystem, and to the atmosphere (i.e., as direct emissions) and forest products sector (i.e., removed from the forest as harvested wood products). Each type of natural disturbance, management disturbance, and land-use change (afforestation and deforestation) in the model is represented by a unique disturbance matrix.

\section{The customized Archive Index Database for the EU (EU-AIDB)}

The AIDB provided with the CBM-CFS3 includes 71 tables described in Kull et al. (2017). This AIDB is tailored to represent the ecological parameters associated with the intersection of Canada's provinces and territories, with the country's terrestrial ecozones, and as such accommodates data and ecological parameters for 48 SPUs (the intersection of 14 administrative boundaries and 18 ecological boundaries). One hundred ninety-four tree species and forest types and 235 disturbance types are represented in this AIDB.

In order to customize the AIDB for applications outside of Canada, the CFS provided supplementary information to assist users in modifying the AIDB tables (Kull et al. 2017). To create a customized AIDB for the EU, we replicated the default AIDB and modified some of the key tables, updating the original information with (i) a complete list of the main European regions (defined at the Nomenclature of territorial units for statistics (NUTS) 2 level for most of EU countriesfor description of NUTS classification, visit ec.europa.eu/ Eurostat/web/nuts/overview); (ii) a new list of ecological boundaries (defined as climatic units (CLUs), and associated with specific climatic parameters, affecting the annual decay rate of DOM pools; and (iii) a list of the main tree species reported by the NFIs for each country. A new set of volumeto-biomass conversion coefficients was developed for each of the tree species, based on the parameters provided by Boudewyn et al. (2007) and Canada's National Forest Inventory (2016), and was incorporated into the new EU-
AIDB (Pilli et al. 2017b). Figure 1 shows the main links and a short description of the tables that were modified in the EUAIDB. The original AIDB values were maintained in all of the other tables, with a few exceptions, i.e., where values were modified on a case by case basis at the country level.

The 14 administrative units included in the original tblAdminBoundaryDefault table were replaced with 204 administrative units, defined at the country level for $26 \mathrm{EU}$ countries, and at the regional level (i.e., at the NUTS 2 level) for 17 countries. For the remaining 9 countries, the administrative units were only defined at the NUTS 0 , i.e., national, level due to the small amount of forest area involved. Additional details are provided in the supplementary materials (see Administrative boundaries worksheet in the supplementary materials).

The 18 ecological boundaries included in the original tblEcoBoundaryDefault table were replaced with 35 CLUs (see Fig. 2). Each CLU was defined by combining precipitation and mean annual temperature values as described in Pilli (2012), i.e., using total monthly precipitation and maximum and minimum monthly temperature values collected by Hijmans et al. (2005). By intersecting CLUs with administrative units, 1034 SPUs were established and entered into the tblSPUDefault table (see "Eco_Admin boundaries" and "Default SPUs" worksheets in the supplementary materials). The default climate data associated with each CLU (see Ecological boundaries worksheet in the supplementary materials) were entered into the tblClimateDefault table in the EU-AIDB.

In order to fully accommodate the new set of SPUs in the EU-AIDB, other related tables were modified, including (i) the tblDMAssociationSPUDefault table, which provides the link between each SPU and the disturbance matrices defined in the EU-AIDB; (ii) the tblSVLAttributesDefaultAfforestation table, which links each SPU with the non-forest soil types, and their initial C stock values (applied whenever non-forest land to be converted to forest land through afforestation is included in a user's inventory); and (iii) the tblDMAssociationDefault table, which associates the disturbance types and disturbance matrices with the ecological boundaries.

The list of tree species in the tblSpeciesTypeDefault table was replaced with 192 European species and forest types. These were identified and included based on the leading species reported in EU country-specific NFIs. A list of the tree species added is included in the supplementary material (see "Species types" worksheet in the supplementary materials).

To estimate the aboveground biomass from the standing merchantable volume-based yield curves, the CBM-CFS3 applies species-specific, stand-level volume-to-biomass conversion equations (Boudewyn et al. 2007, Canada's National Forest Inventory 2016) defined for each ecozone and administrative boundary. When some ancillary data (e.g., direct biomass measurements, specific biomass expansion factors, or allometric equations) were available in the NFI, or scientific literature, a new tree species or forest type was associated with an appropriate 


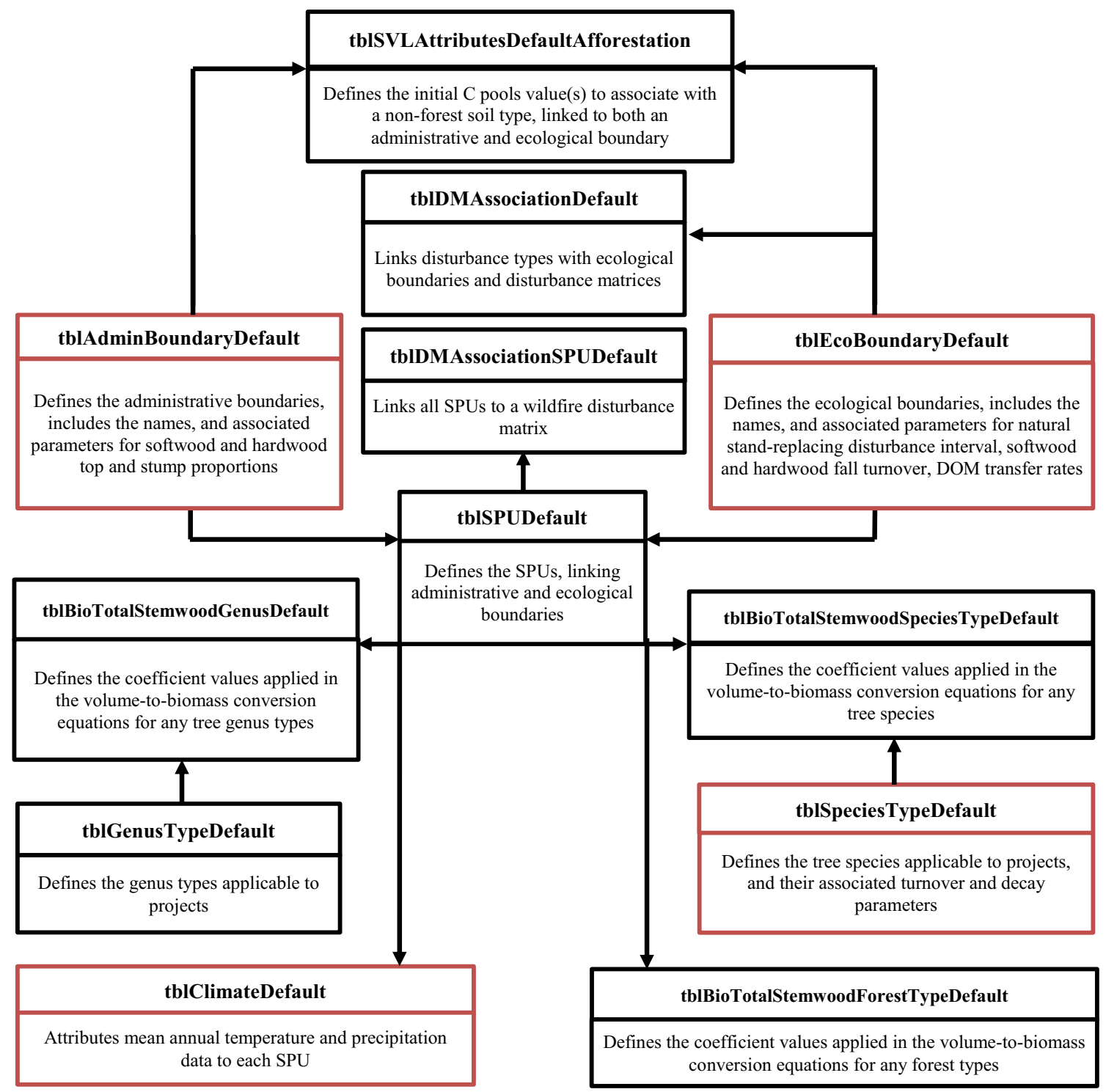

Fig. 1 Key (red outline) and contributing (black outline) tables modified in the EU Archive Index Database (EU-AIDB, Pilli et al. 2017b), and their descriptions and main relationships

allometric equation by using the NFI's volume as an independent variable, and by comparing country-specific values of biomass with the biomass calculated using the 192 allometric equations constructed by Boudewyn et al. (2007) for the province of Quebec (as reported in the tblBioTotalStemwoodSpeciesType table of the AIDB, and in the tblBioTotalStemwoodSpeciesType worksheet in the supplementary materials). For each species or forest type added, equation coefficients were selected that minimized the difference (i.e., the sum of squares) between the predicted values by selected coefficients and the country's observed values of biomass (the approach is described in Appendix D of Pilli et al. 2013). If no additional data on the species or forest type were available from a country, it was assumed that the same coefficients would be selected for a similar species or forest type in another country (see "Species types" worksheet in the supplementary materials).
Each new species or forest type was linked to a genus identifier (in the tblGenusTypeDefault table), and to the coefficients used to convert the volume to biomass, according to the equations defined by Boudewyn et al. (2007) for Quebec. To achieve this, the following EU-AIDB tables were modified: tblBioTotalStemwoodForestTypeDefault, tblBioTotalStemwoodGenusDefault, and tblBioTotalStemwood SpeciesTypeDefault.

Data availability The database can be accessed at http://data. europa.eu/89h/jrc-cbm-eu-aidb (Pilli et al. 2017b), primary metadata are available in Kull et al. (2017), and additional metadata are available at https://metadata-afs.nancy.inra.fr/ geonetwork/srv/fre/catalog.search\#/metadata/df48155b-973f4169-a722-100bb6bfc76c. 
Fig. 2 Overview map of the geographic distribution of the 60 CLUs identified at the European level, including 35 CLUs associated with forest area (see the supplementary materials for additional information)

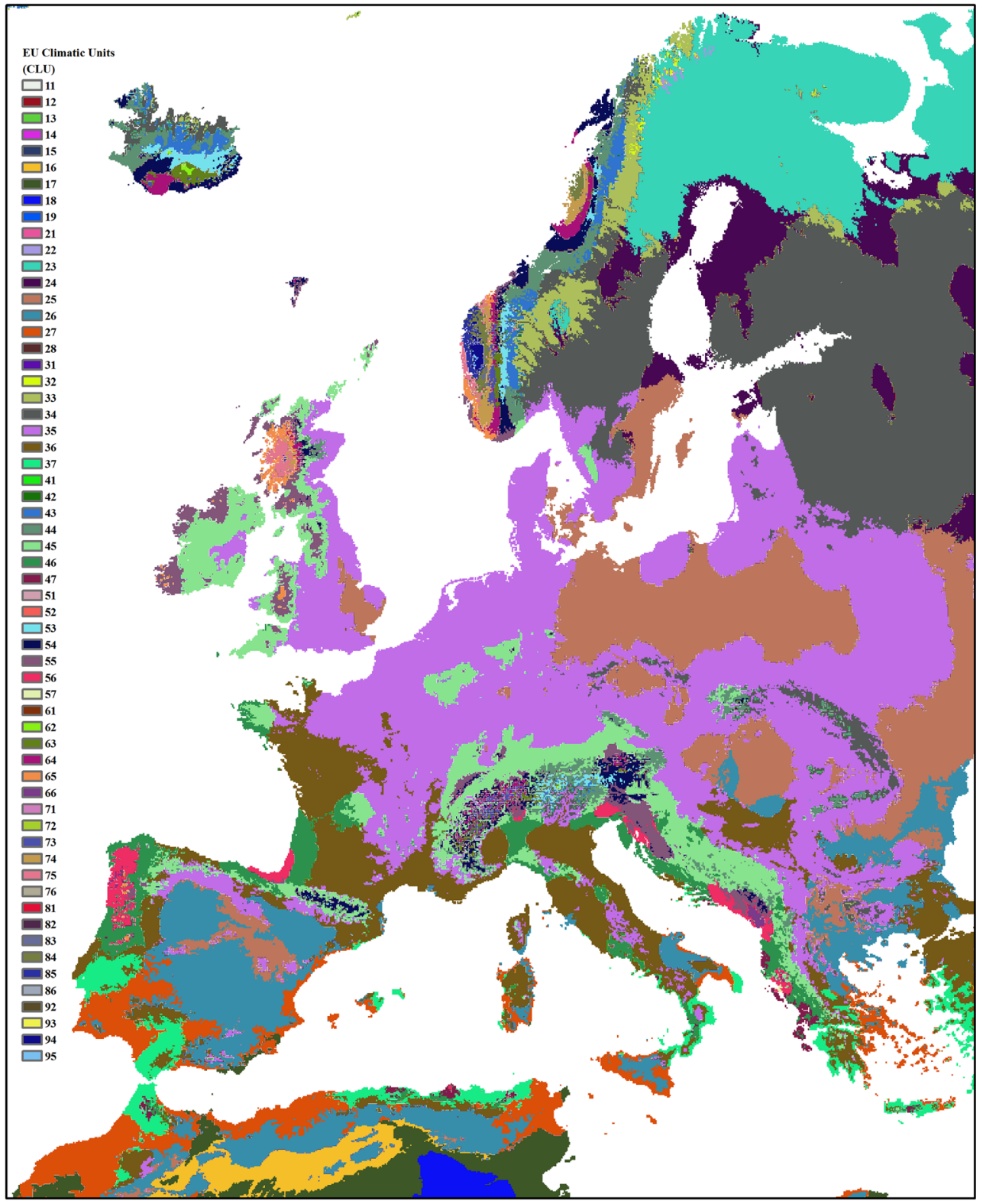

\section{Discussion}

Customizing the AIDB at country level required a preliminary assessment to identify the key tables to be updated (in our case, the tblAdminBoundaryDefault, tblClimateDefault, tblEcoBoundaryDefault, and tblSpeciesTypeDefault) and the main tables linked to the previous group. We prioritized our effort on the living biomass pool, since this directly affects all of the other pools in forest ecosystem and represents the main component in determining the forest $\mathrm{C}$ stocks and stock changes. As well, it was assumed that the soil-related $\mathrm{C}$ pools (litter, dead wood, soil organic matter) would not change over time on a large scale without significant changes in management (IPCC 2006). We ensured that the changes and updates in the EU-AIDB were consistent and functional by repeatedly using this database in numerous studies performed at the country and EU levels (Pilli et al. 2013, 2016, 2017a). However, as errors and inconsistences in existing data are possible, and new data may become available at the country level, the EU-AIDB will be under ongoing revision.

If information on the administrative units are easily accessible, combining these data with climatic parameters will require some further elaboration and assumptions. Since the objective of our study was to harmonize the AIDB at the EU level, we first defined a common set of spatially explicit climatic units, and then we defined each SPU by overlapping it with the available administrative units. If spatially explicit NFI data are not available, combining each SPU with this information may be challenging. In our case, by associating the NFI forest area with each CLU on the basis of the CORINE Land 
Cover map (Pilli 2012), we ensured that the EU-AIDB incorporated all of the possible climate and administrative units containing forest area.

Having access to NFI plot data, including both volume and biomass measurements (if possible, for stemwood, bark, branches, and foliage), specific allometric equations could be developed by applying the same model proposed by Boudewyn et al. (2007), and updating all of the parameters reported by the default tables with new values. Even if some studies found this processing inappropriate for field measurements (e.g., Di Cosmo et al. 2016), it is recommended when the CBM-CFS3 is intended for local/ small-scale applications, or whenever the focus is on an accurate assessment of the soil $\mathrm{C}$ pool. Because this requires additional resources, and in our case, such underlying information were not available, a second option is to couple the NFI's volume with observed or estimated values of biomass to associate each new species with an existing allometric equation. In the development of the EU-AIDB, this approach was applied to 9 out of 26 countries and took into account the specific definitions of volume and biomass applied at the country level (i.e., the inclusion of bark, tops, and branches), and the values expected by the CBM-CFS3. The last option, applied to the remaining countries, was to associate the new species with a similar species in another country on the bases of ecological similarities and expert assessment. This would also be possible without modifying the default parameters in the original AIDB, for example, spruce could be directly associated with the default parameters corresponding to the same species in the original AIDB.

Customizing the DOM parameters, defining the transfer rate from living biomass to and between DOM pools, and the loss of DOM from these pools through decomposition to the atmosphere, is even more challenging. Indeed, this requires further analysis (White et al. 2008; Smyth et al. 2010) and field data, possibly referenced to each CLU. Since these data, generally collected at the local level, were not available in our case, they can only be modified when the AIDB is applied to specific case studies.

Similarly, due to a lack of specific information, we did not modify the default disturbance matrices and assumed a general similar typology of $\mathrm{C}$ transfers among pools for each family of disturbances (i.e., natural or management disturbance events) across Canada and Europe. Appropriate disturbances can easily be selected from existing ones in the CBM-CFS3, and each user should accurately check and, eventually, modify the corresponding disturbance matrix to mimic as much as possible the carbon transfers related to each natural and humaninduced disturbance event, according to the local conditions.

\section{Conclusions}

In the CBM-CFS3 interface, the default Canadian AIDB can be easily replaced with the EU-AIDB for direct application to new CBM-CFS3 projects created for an EU country or region, i.e., by using the new administrative and ecological boundaries, and forest types implemented in the database (see note entitled, "Selecting an archive index database" in section 2.4 of Kull et al. 2016). The EU-AIDB is specifically designed for use by EU countries who wish to use the CBM-CFS3 to support policy development and research activities as it relates to forest ecosystem greenhouse gasses. In addition, the EUAIDB can be used in preliminary applications of the CBMCFS3 for testing purposes, where result analysis and comparison to field data may lead to additional EU-AIDB modifications. This represents a first step to fully customize the model for a specific EU country or region. Future improvements may include a more detailed selection of the volume-to-biomass allometric equations based on data collected at the local level, or a more refined definition of the climatic and administrative boundaries. Biomass turnover rates and dead organic matter parameters were not modified in the EU-AIDB, presenting an opportunity for database improvements which could lead to better comparisons of results with other models. The information contained in this database, which is spatially referenced to climatic and administrative units, with an indirect link to the main forest types identified at EU level, could also be used for large-scale studies combining forest maps with climatic, administrative, and management information. It could also be used to back-calculate biomass expansion factors based on the current allometric equations, for comparison with other studies, or it could be used where these parameters are absent. Overall, it is intended that the availability of this EU-AIDB will increase the transparency of our past and future research, and allow further application of the CBM-CFS3 at the national and local levels in EU countries.

Acknowledgements We especially thank Werner Kurz, Carolyn Smyth, and the CFS Carbon Accounting Team for their indispensable technical support with these studies. We also thank Sarah Mubareka and Andrea Perego for the technical support in the preparation of the web site.

Funding information This database was prepared in the context of various contracts between the JRC and DG CLIMA: AA 071201/2011/ 611111/CLIMA.A2 and 070307/2009/539525/AA/C5.

\section{Compliance with ethical standards}

Competing interest The authors declare that they have no competing interests. The views expressed are purely those of the authors, and may not under any circumstances be regarded as stating an official position of the European Commission or Natural Resources Canada.

Open Access This article is distributed under the terms of the Creative Commons Attribution 4.0 International License (http:// creativecommons.org/licenses/by/4.0/), which permits unrestricted use, 
distribution, and reproduction in any medium, provided you give appropriate credit to the original author(s) and the source, provide a link to the Creative Commons license, and indicate if changes were made.

\section{References}

Boudewyn PA, Song X, Magnussen S, Gillis MD (2007) Model-based, volume-to-biomass conversion for forested and vegetated land in Canada. Nat. Resour. Can., Can. For. Serv., Pac. For. Cent., Victoria, BC. Inf. Rep. BC-X-411. [http://cfs.nrcan.gc.ca/ publications/?id=27434]

Canada's National Forest Inventory (2016) Biomass calculator: modelbased, volume-to-biomass conversion for forested and vegetated land in Canada. [https://nfi.nfis.org/en/biomass_models]

Di Cosmo L, Gasparini P, Tabacchi G (2016) A national-scale, stand-level model to predict total above-ground tree biomass from growing stock volume. For Ecol Manag 361:269-276. https://doi.org/10. 1016/j.foreco.2015.11.008

Hijmans R, Cameron SE, Parra JL, Jones PG, Jarvis A (2005) Very high resolution interpolated climate surfaces for global land areas. Int $\mathrm{J}$ Climatol 25:1965-1978. https://doi.org/10.1002/joc.1276

IPCC (Intergovernmental Panel on Climate Change) (2006) In: Eggleston S, Buendia L, Miwa K, Ngara T, Tanabe K (eds) Guidelines for national greenhouse gas inventories. Institute for Global Environmental Strategies, Hayama

IPCC (Intergovernmental Panel on Climate Change) (2014) In: Hiraishi T, Krug T, Tanabe K, Srivastava N, Baasansuren J, Fukuda M, Troxler TG (eds) Revised supplementary methods and good practice guidance arising from the Kyoto Protocol, 2013, Switzerland

Karjalainen T, Pussinen A, Liski J, Nabuurs G-N, Eggers T, Lapveteläinen T, Kaipainen T (2003) Scenario analysis of the impacts of forest management and climate change on the European forest sector carbon budget. For Pol Econ 5:141-155. https://doi. org/10.1016/S1389-9341(03)00021-2

Kim M, Lee WK, Kurz WA, Kwak DA, Morken S, Smyth CE, Ryu D (2016) Estimating carbon dynamics in forest carbon pools under IPCC standards in South Korea using CBM-CFS3. iForest 10(1): 83-92. https://doi.org/10.3832/ifor2040-009.

Kull SJ, Rampley G, Morken S, Metsaranta J, Neilson ET, Kurz WA (2016) Operational-scale Carbon Budget Model of the Canadian Forest Sector (CBM-CFS3) version 1.2: user's guide. Nat. Resour. Can., Can. For. Serv., North. For. Cent., Edmonton, AB

Kull SJ, Morken S, Smyth CE, Fellows M (2017) Carbon Budget Model of the Canadian Forest Sector (CBM-CFS3): Archive Index Database table and parameter descriptions. Nat. Resour. Can., Can. For. Serv., North. For. Cent., Edmonton, AB

Kurz WA, Apps MJ (1999) A 70-year retrospective analysis of carbon fluxes in the Canadian forest sector. Ecol Appl 9(2):526-547. https://doi.org/10.1890/1051-0761(1999)009[0526: AYRAOC]2.0.CO;2

Kurz WA, Apps MJ, Webb TM, McNamee PJ (1992) The carbon budget model of the Canadian forest sector: phase I. Forestry Canada, Northwest Region, North. For. Cent., Edmonton, AB. Information Report NOR-X-326E. 93 p

Kurz WA, Dymond CC, Stinson G, Rampley GJ, Neilson ET, Carroll AL, Ebata T, Safranyik L (2008a) Mountain pine beetle and forest carbon feedback to climate change. Nature 452:987-990. https://doi.org/10. 1038/nature06777

Kurz, WA, Stinson G, Rampley GJ, Dymond CC, Neilson ET (2008b) Risk of natural disturbances makes future contribution of Canada's forests to the global carbon cycle highly uncertain. Proceedings of the National Academy of Sciences of the United States of America, 105, 1551-1555. DOI: https://doi.org/10.1073/pnas.0708133105

Kurz WA, Dymond CC, White TM, Stinson G, Shaw CH, Rampley GJ, Smyth C, Simpson BN, Neilson ET, Trofymow JA, Metsaranta J, Apps MJ (2009) CBM-CFS3: a model of carbon-dynamics in forestry and land-use change implementing IPCC standards. Ecol Model 220(4):480-504. https://doi.org/10.1016/j.ecolmodel.2008. 10.018

Li Z, Kurz WA, Apps MJ, Beukema SJ (2003) Belowground biomass dynamics in the Carbon Budget Model of the Canadian Forest Sector: recent improvements and implications for the estimation of NPP and NEP. Can J For Res 33:126-136. https://doi.org/10.1139/ X02-165

Penman J, Gytarsky M, Hiraishi T, Krug T, Kruger D, Pipatti R, Buendia L, Miwa K, Ngara T, Tanabe K, Wagner F (eds) (2003) Good practice guidance for land use, land-use change and forestry. Intergovernmental Panel on Climate Change (IPCC), National Greenhouse Gas Inventories Programme, Institute for Global Environmental Strategies, Kanagawa

Pilli R (2012) Calibrating CORINE Land Cover 2000 on forest inventories and climatic data: an example for Italy. Int J Appl Earth Obs Geoinf 9:59-71. https://doi.org/10.1186/s13021-015-0016-7

Pilli R, Grassi G, Kurz WA, Smyth CE, Blujdea V (2013) Application of the CBM-CFS3 to estimate Italy's forest carbon budget, 1995 to 2020. Ecol Model 266:144-171. https://doi.org/10.1016/j. ecolmodel.2013.07.007

Pilli R, Grassi G, Cescatti A (2014) Historical analysis and modeling of the forest carbon dynamics using the Carbon Budget Model: an example for the Trento Province (NE, Italy). Forest 11:20-35. (published in Italian with summary in English). https://doi.org/10.3832/ efor1138-011

Pilli R, Grassi G, Kurz WA, Viñas RA, Guerrero N (2016) Modelling forest carbon stock changes as affected by harvest and natural disturbances. I. Comparison with countries' estimates for forest management. Carbon Balance Manag 11:5. https://doi.org/10.1186/ s13021-016-0047-8

Pilli R, Grassi G, Kurz WA, Fiorese G, Cescatti A (2017a) The European forest sector: past and future carbon budget and fluxes under different management scenarios. Biogeosciences 14:2387-2405. https:// doi.org/10.5194/bg-14-2387-2017.

Pilli R, Kull S, Blujdea V, Grassi G (2017b) The EU Archive Index Database customised for the Carbon Budget Model (CBM-CFS3). European Commission, Joint Research Centre (JRC) [dataset] PID: http://data.europa.eu/89h/jrc-cbm-eu-aidb

Smyth CE, Trofymow JA, Kurz WA (2010) Decreasing uncertainty in CBM-CF s3 estimates of forest soil carbon sources and sinks through use of long-term data from the Canadian Intersite Decomposition Experiment. Pacific Forestry Centre, Information Report BC-X-422. [http://cfs.nrcan.gc.ca/pubwarehouse/pdfs/ 31205.pdf]

Stinson G, Kurz WA, Smyth CE, Neilson ET, Dymond CC, Metsaranta JM, Boisvenue C, Rampley GJ, Li Q, White TM, Blain D (2011) An inventory-based analysis of Canada's managed forest carbon dynamics, 1990 to 2008. Glob Chang Biol 17(6):2227-2244. https:// doi.org/10.1111/j.1365-2486.2010.02369.x

White T, Luckai N, Larocque GR, Kurz WA, Smyth C (2008) A practical approach for assessing the sensitivity of the Carbon Budget Model of the Canadian Forest Sector (CBM-CFS3). Ecol Model 219(3): 373-382. https://doi.org/10.1016/j.ecolmodel.2008.07.012

Zamolodchikov DG, Grabovsky VI, Korovin GN, Kurz WA (2008) Assessment and projection of carbon budget in forests of Vologda Region using the Canadian model CBM-CFS. Lesovedenie 6:3-14 (published in Russian with summary in English) 